\title{
28 Research Square \\ Failure of labor induction in Tigray region, Ethiopia: a retrospective record review study
}

Teklehaymanot Huluf Abraha ( $\nabla$ teklehaymanothuluf@gmail.com )

Aksum University https://orcid.org/0000-0003-0868-1659

Wondwossen Wollie Kasahun

Aksum University

Gezienesh Kahsay Fisseha

Aksum University

Research

Keywords: Failure, induction of labour, factors, Tigray , Ethiopia

Posted Date: October 8th, 2020

DOI: https://doi.org/10.21203/rs.3.rs-86681/v1

License: (c) (1) This work is licensed under a Creative Commons Attribution 4.0 International License.

Read Full License 


\section{Abstract}

Background: Failed induction of labour is defined as when there is failure to generate regular contractions (i.e, every 3 minute) and cervical change after artificial membrane rupture and at least 24 hour of oxytocin use However, the magnitude of failed induction labor in Tigray is not well documented. Therefore, the objective of this study was to assess the magnitude and factors associated with failed induction of labor in the study area.

Methods: We conducted institution-based- retrospective record review study of all inductions of labor conducted from April 9, 2017- April 8, 2018( $n=380)$ in Axum St.Mary hospital, Tigray, Ethiopia. Data were entered and analyzed using SPSS version 21 software. The data were cleaned before analysis. Descriptive statistics such as frequency and mean were used to describe the study participants. For the multivariable logistic, binary logistic regression a two tailed $p$-value $<0.05$ was performed to show statistical significant.

Results: The magnitude of failure of labor induction was found $11.8 \%$ (95\% Cl: 8.7-15.3\%). The multivariable binary logistic regression analysis showed that primi-parity (AOR=4.31, 95\% Cl; 1.22-15.18) and poor Bishop Score (AOR=10.67, 95\%Cl: 1.31-86.87) were significantly associated with failed induction of labor.

Conclusion and recommendation: The failed of labor induction was found high in the study area. The health care providers should assess and document the status of the cervix (using the Bishop score) to determine the probability of success and to select the appropriate method of induction. In addition, they need to consider induction of women with an unfavorable cervix is associated with high failure and a higher caesarean section.

\section{Plain English Summary}

Induction of labour is indicated where the benefits to mother and / or fetus of discontinuing the pregnancy outweigh the risks of awaiting a spontaneous onset of labour and is one of the most common obstetric practice that occurred during pregnancy. Epidemiologically speaking labour has to be induced about $20 \%$ of pregnancies. However, induction fails in $20 \%$ of induced pregnancies. Failed induction of labour should considered only when there is failure to generate regular contractions (i.e, every 3 minute) and cervical change after artificial membrane rupture and at least 24 hour of oxytocin use. Despite wide spread of obstetric practice (i.e, induction of labour), not much is known about the magnitude and factors associated with failed induction in Tigray region. Therefore, the objective of this study was to assess the magnitude of failure of labor induction and associated factors among women who undergone induction of labour (IOL) after 28 weeks of gestation at Axum St. Marry hospital from April 9, 2017- April 8, 2018,Tigray, Ethiopia.

An institutional based cross-sectional study was conducted by reviewing records of term and post-term delivers from April 9, 2017- April 8, 2018( $n=380)$. All samples were taken from this period. Consecutive 
sampling technique was employed to select the study participants. Data were cleaned, entered and analyzed using SPSS version 12 software. Descriptive statistics was applied to characterize the study variables. Three hundred seventy nine of the study participants were Tigray by ethnicity. Almost all, $379(99.7 \%)$ study participants were married. The mean gestational age was $38.34 \pm 2.66$ weeks. Majority of $(60.8 \%)$ the gestational age ranged from $37-41$ weeks. In this study the proportion of failure of labor induction was found $11.8 \%$ (95\% Cl: $8.7-15.3 \%$ ). Primi-parity and poor Bishop score were significantly and independently associated with failure induction of labor. The finding suggest health care providers should assess and document the status of the cervix (using the Bishop score) to determine the probability of success and to select the appropriate method of induction. In conclusion, results from this study may help obstetricians, midwifes and public health experts to improve the outcome of induction of labour, and maternal and perinatal health.

\section{Background}

According the World Health Organization (WHO), induction of labour ( $\mathrm{IOL}$ ) is defined as the process of artificially stimulating the uterus to start labour. It is a useful obstetric intervention and usually performed by administering oxytocin of prostaglandins to the pregnant women or by manually rupturing the amniotic members[1]. The reason for and method of induction should be discussed between the services provider and the woman in order to obtain clear consent.

Induction of labour should be used only when the benefits to the fetus or mother of the baby outweigh those of the pregnancy continuing[1-3]. Induction of labour has become an increasingly utilized obstetric intervention[4, 5]. Induction maybe advocated to reduce fetal or neonatal morbidity and mortality as with post-term pregnancy, oligohydramnios, suspected intrauterine growth restriction (IUGR) and fetal gastroschisis, to reduce maternal morbidity, as with maternal cardiac disease and preeclampsia/eclampsia, or to benefit both maternal and fetal as with pre-labour rupture of membranes (PROM) at term and fetal macro-somia. However, the major risks associated with induction of labour include: increased cesarean section and instrumental delivery, chorioamnionitis, techysystole with abnormal fetal heart rate patterns, uterine atony, increased cost, and uterine rupture[1, 6]. Induction to be successful, the cervix needs to have undergone the changes that will ensure contractions are effective in the progressive dilation and effacement of the cervix $[7,8]$.

Failed induction is strongly associated with maternal and perinatal complication [4], and increased rate of instrumental deliveries and caesarean sections [9].In Ethiopia, induction of labor (IOL) has become an increasingly performed obstetric intervention [10-12]. Oxytocin is the most common agent used for induction of labor. The rate of failed induction varies was indicated in Addis Ababa (28.4\%) [12], 21.4\% Jimma town[10], and Hawassa 17.3\% [11]. Research evidence showed that, maternal factors( such as primi parity, maternal age, poor Bishop Score, fetal factors(such as birth weight and gestational age) [11] and primigravida, and poor Bishop score $[10,11,13-18]$ have been suggested to predict failed induction. Failure is a concern for all health care professional and accurate of failure is still a difficult task for the health care cadre. In the study area, induction of labour is a commonly done procedure but there a 
limitation in undertaking a study on the level and factors associated with its failure of labour induction in Tigray region particular in the study area. Therefore, the aim of the study is to answer the following research questions :I) what is the magnitude of failed induction labor, II) what are the factors affecting failed induction in the study area; identify predictors to make recommendations for practice, which we may hopefully reduce complication related to induction of labor.

\section{Methods}

\section{Study context}

The study was conducted in Axum St.Marry hopsital found in Aksum town. Aksum is the most ancient town of Ethiopia, found in Tigray national regional state about $1024 \mathrm{~km}$ from Addis Ababa and $247 \mathrm{~km}$ from Mekelle, which is the capital city of Tigray regional state. In the town, there were one referral and teaching hospital, one Zonal hospital (Axum St. Marry), two health centers, and nine different level private clinics. Axum St. Mary hospital is a governmental zonal hospital established in 1966 G.C. The hospital has four main department's internal medicine, pediatric, gynecologic/ obstetric and surgery. It has also dental, physiotherapy and psychiatric departments.

\section{Study Design And Period}

A retrospective cross-sectional study with analytic component was employed. The study was conducted from April 9, 2017- April 8, 2018. The data collection period was from March 10- May 9, 2018.

\section{Source population}

The source population of the study was all women who undergone IOL after 28 weeks of gestation at Axum St. Marry hospital from April 9, 2017- April 8, 2018.

\section{Study Population}

The study population was all systematically selected women who undergone induction of labor after 28weeks of gestation in Axum St.Marry hospital from April 9, 2017- April 8, 2018.

\section{Eligibility Criteria}

\section{Inclusion criteria}

All registered women who had IOL after 28 weeks of gestation in Axum St.Marry hospital maternity ward from April 9, 2017- April 8, 2018.

\section{Exclusion Criteria}

All registered women who had induction of labor without full documentation. Development of nonreassuring fetal heart rate pattern (NRFHRP) after initiation of induction of labor $(n=380)$.

\section{Sample Size Calculation And Sampling Technique}


A cross-sectional study was conducted by reviewing records of term post-term delivers from April 9, 2017April $8,2018(n=380)$. All samples were taken from this period. Consecutive sampling technique was employed to select the study participants.

\section{Operational Definitions}

\section{Induction of labor (IOL)}

Refers to the iatrogenic stimulation of uterine contractions before the onset of spontaneous labor to accomplish vaginal delivery after 28 weeks of gestation $[1,4]$.

\section{Apgar score}

A scoring system devised by Dr Virginia Apgar based on five criteria (heart rate, respiration, color, muscle tone and response to stimulation) and used as a marker of a newborn baby's need for resuscitation at birth. A score of 0,1 or 2 is awarded for each criterion, with a total score out of ten. The score is assessed at 1 and 5 minutes after birth. It is stratified as very low Apgar scores (0-3), low Apgar scores (4-6) and normal range $(>7)[19]$.

\section{Failed induction of labor}

Failure to generate regular contractions (i.e. every 3 minute) and cervical change with oxytocin administration for 12 hours after rupture of membranes. Cesearean section (CS) was done if there was a failure to go into active phase labor or fetal distress / maternal risk exceeded the induction process benefits $[13,20,21]$. And also it was the dependent variable in this study and this information was obtained from medical record. It was categorized as "yes" and "no" with code of 1 and 0 respectively.

\section{Gestational age}

Is calculated from the last normal menstrual period (LNMP) that was documented on the card or ultrasound estimation if not from the duration of amenorrhea documented from mother's recall \& is rounded to the nearest weeks. Amenorrhea of 9 months was taken as 40 weeks' gestation for all mothers [22].

\section{Post term pregnancy}

A pregnancy lasting $>42$ weeks [23].

\section{Parity}

Fetus delivered after 28 weeks of gestation for Ethiopia.

\section{Data Collection Tools And Quality Control}


The data were collected by secondary data sources (document review) using a structured questioners composed of socio demographic and obstetric variables of women who undergone induction of labour. The questionnaires were prepared in English version from similar study [10, 11, 14, 24]. A pre-tested questioner was used on $5 \%$ of the sample size in (i.e. Wukro Maray primary hospital) and necessary intervention was done before the data collection. The data collectors were two BSc midwife and supervised by one BSc midwife to follow the data collection process. The investigators and supervisor were checked data accuracy, consistency and completeness daily.

\section{Statistical analysis}

The collected data were entered and analyzed using SPSS version 21. The data were cleaned before analysis.

Descriptive statistics such as frequency and mean were used to describe the study participants. Crude and adjusted odds ratios (95\%) confidence intervals were utilized to assess the determinant factors with the failed induction of labour. The criterion for selecting independent variables was set at $p$-value less than 0.25 in bivariable analysis for final model model. To control for potential confounder, a multivariable binary logistic regression was performed. A two tailed $p$-value $<0.05$ was performed to show statistical significant. Model fitness was performed with Hosmer- Lemshow test. And also multicollinearity was checked using at $<10$ variance inflation factor (VIF). There were no variables that have VIF greater than 10.

\section{Results}

\section{Socio-demographic related characteristics}

A 380 record of mother's document was reviewed during the study period. The chart retrieval rate was $100 \%$. The age of the study participants was ranges from 18-45 years and their mean age was 29.24 ( \pm 6.2) years. Of these, 353(92.9\%) were Orthodox Christian. Three hundred seventy nine (99.7\%) the participants belong to Tigray ethnicity. Almost all, 379(99.7\%) study participants were married. In addition, majority of the study participants were urban resident [Table 1]. 
Table 1

Socio-demographic characteristics women who undergone induction of labor from April 9, 2017- April 8, 2018 in Axum St. Marry hospital $(n=380)$.

\begin{tabular}{|llll|}
\hline Characteristics & Category & Frequency $(\mathbf{n}=380)$ & Percentage $(\%)$ \\
\hline \multirow{2}{*}{ Age } & $\leq 30$ & 227 & 59.7 \\
\cline { 2 - 4 } & $>30$ & 153 & 40.3 \\
\multirow{2}{*}{ Eeligion } & Orthodox Christian & 353 & 92.9 \\
\cline { 2 - 4 } & Muslim & 27 & 7.1 \\
\hline \multirow{2}{*}{ Residency } & Tigray & 379 & 99.7 \\
\cline { 2 - 4 } & Amhara & 1 & 0.3 \\
\cline { 2 - 4 } Marital status & Murban & 235 & 61.8 \\
\hline & Single & 145 & 38.2 \\
\hline
\end{tabular}

\section{Obstetric Descriptive Statistics}

The mean gestational age was $38.34 \pm 2.66$ weeks (range: $32-44$ weeks). Majority of $(60.8 \%)$ the gestational age ranged from $37-41$ weeks. Off the 380 women, two hundred ninety six $(77.9 \%)$ were multiparty. One hundred forty seven (38.7\%) women have recorded regarding the bishop score [Table].

The top four indications for undergoing induction in this study were hypertensive disorders of pregnancy (41.1\%), post-term (23.4\%), premature rapture of membrane (PROM) (17.8\%) and APH (13.7\%) [Figure1]. Regarding the method of induction, One hundred ninety four (51.1\%) of the women had been reported as received intravenous oxytocin followed by one hundred eighty four (48.4\%) received prostaglandins. 
Table 2

Obstetric descriptive statistics of women who undergone induction of labour from April 9, 2017- April 8, 2018 in Axum St.Marry hospital ( $n=$ 380).

\begin{tabular}{|llll|}
\hline Characteristics & Category & Frequency (n) & Percentage (\%) \\
\hline Parity & Primi & 84 & 22.1 \\
\cline { 2 - 4 } Gestational age & Multi & 296 & 77.9 \\
& $\leq 36$ & 60 & 15.8 \\
\cline { 2 - 4 } & $37-41$ & 231 & 60.8 \\
\hline ROM before IOL & Yes & 89 & 23.4 \\
\cline { 2 - 4 } & No & 63 & 16.6 \\
\cline { 2 - 4 } & Not recorded & 5 & 82 \\
\hline Liquor foul smell & Yes & 5 & 1.4 \\
\cline { 2 - 4 } & No & 345 & 1.3 \\
\cline { 2 - 4 } & Not recorded & 30 & 90.8 \\
\hline Bishop score & $\leq 5$ & 78 & 7.9 \\
\cline { 2 - 4 } & $>5$ & 69 & 20.5 \\
\cline { 2 - 4 } & Not recorded & 233 & 18.2 \\
\hline Misoprostol routes & Vaginal & 167 & 61.3 \\
\hline & Sub lingual & 17 & 90.7 \\
\hline & & & 9.3 \\
\hline
\end{tabular}




\begin{tabular}{|llll|}
\hline Total dose of misoprostol & 25ug & $\mathbf{8}$ & 4.3 \\
\hline & $50 u g$ & 37 & 20.1 \\
\hline & $75 u g$ & 73 & 39.7 \\
\hline Mode of delivery & 100ug & 58 & 31.5 \\
\hline & $>100 u g$ & 8 & 4.3 \\
\hline Newborn status at birth & Vaginally delivered & 335 & 88.2 \\
\hline Birth weight of newborn & Cesearean section & 45 & 11.8 \\
\hline & Slive & 371 & 97.6 \\
\hline Newborn admitted to NICU & Yes & 9 & 2.4 \\
\hline & No00 g & 8 & 2.1 \\
\hline Reason for admission to NICU & Low birth weight & 372 & 97.9 \\
\hline & Respiratory Distress Syndrome (RDS) & 15 & 48.4 \\
\hline
\end{tabular}

\section{Magnitude Of Failed Induction Labor}

Of the 380 study participants, 196(51.6\%) had been received intravenous oxytocin followed by $184(48.4 \%)$ received prostaglandins. Three hundred thirty fife (88.2\%) of the women delivered vaginally and forty five (11.8\%) under gone cesearean section (CS) due to failed induction of labor. Three hundred seventy one $(97.6 \%)$ and nine $(2.4 \%)$ of them were born alive still birth respectively. Among the live births; thirty one (8.4\%) had APGAR score of $\leq 7$ in the 1 st and 5 th. Twelve (3.2\%) of the neonates were admitted to newborn intensive care unit (NICU) with the main reason being preterm followed by respiratory distress syndrome.

\section{Factors Associated With Failed Induction Of Labor}

The results of bivariate logistic regression analysis showed the following factors on socio-demographic and obstetric characteristics had significant association with failed induction of labor. These were maternal age [COR $=2.61,95 \% \mathrm{Cl}: 1.24-5.43]$, parity [COR $=4.696(2.459-8.969]$, bishop score [COR $=$ $8.64,95 \% \mathrm{Cl} 1.91-39.13)]$, New born birth weight [COR $=25.615,95 \% \mathrm{Cl}: 4.997-131.304]$, and rupture of membrane before IOL $[\mathrm{COR}=4.67,95 \% \mathrm{Cl}: 1.10-19.83]$. 
In the final model (multivariable logistic regression) analysis, parity and bishop score were significantly and independently associated with failed induction of labor. Women who had primi parity were 4.31 times (AOR $=4.31,95 \% \mathrm{Cl}: 1.22-15.18)$ more likely to have failed induction as compared to multi-parity. The odds of failed induction of labour were 10 times more likely in women with Bishop score of 5 or less as compared to Bishop score $>5(\mathrm{AOR}=10.12,95 \% \mathrm{Cl}: 1.31-86.87)>5$ [Table 3] .

Table 3

Factors associated with failed induction of labor among women who undergone induction of labor from April 9, 2017- April 8, 2018 in Axum St.Marry hospital( $\mathrm{n}=380)$.

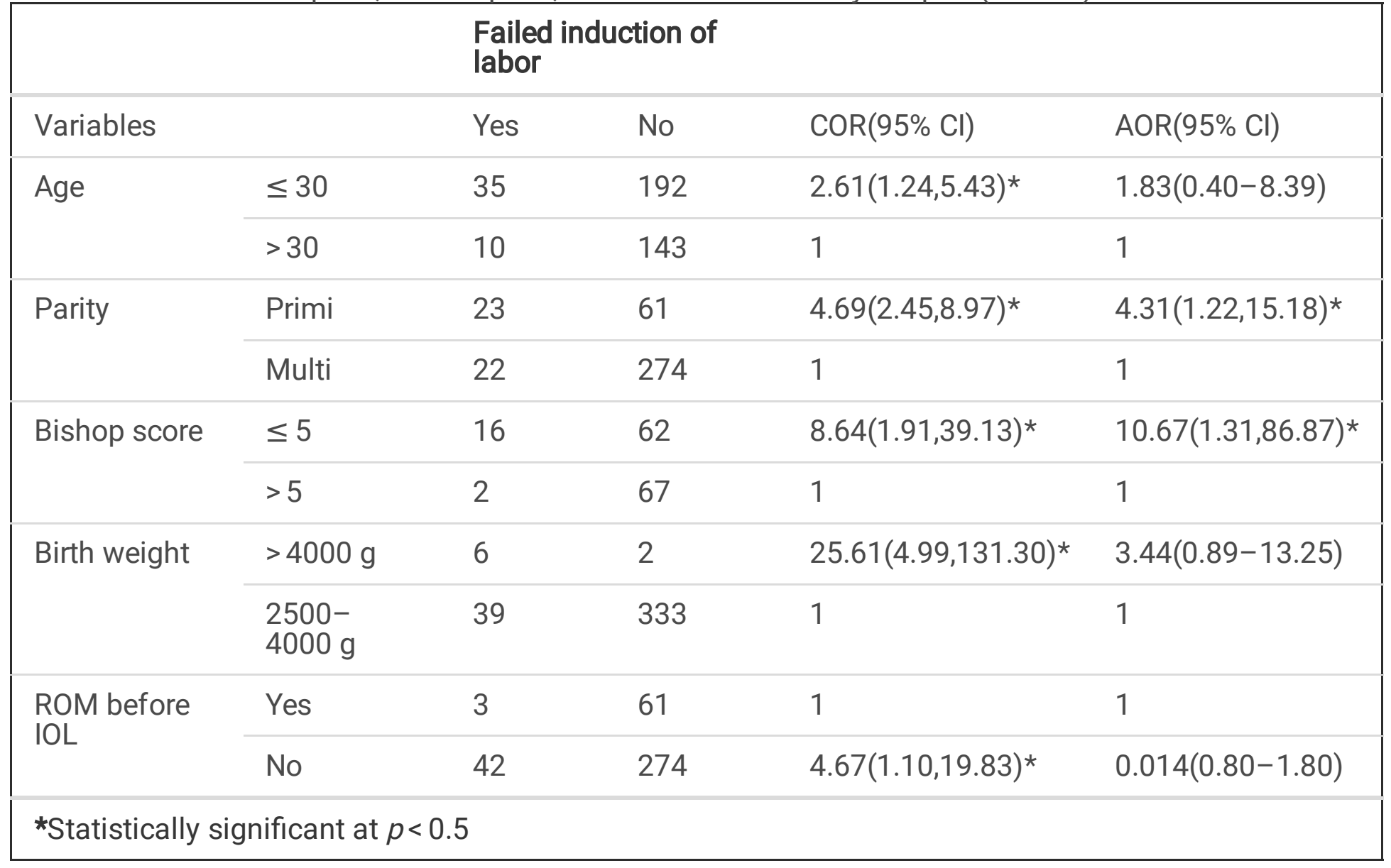

\section{Discussion}

One of the contributing factors for increasing rate of $\mathrm{IOL}$ is the concern of the patient and health services providers about the possible risk of fetal death at term or postdate with the expectant management[6-8, 25]. However the magnitude and determinants of failed labour of induction is not well documented in the study area. Hence, the overall aim of this study was designed to review the magnitude and factors affecting of failed induction. The magnitude of failure of labor induction was found $11.8 \%$. In multivariable logistic regression primipara and poor Bishop score were the predictors for failed induction of labor. 
This study revealed that, the proportion of failure of labor induction was $11.8 \%$ (95\% Cl: $8.7-15.3 \%$ ); this finding was lower than the finding of Jimma (21.4\%)[10], Hawassa (17.3\%)[11], Addis Ababa (28.4\%) [12], Nigeria(18\%) [26] and Pakistan(18\%)[14]. This is because of correctly maintaining the oxytocin concentration during the changes of the bag while the infusion bag is completed. In addition appropriate storage of oxytocin could be other reason[10].

The main indications for induction of labor were hypertensive disorder, post-term pregnancy, pre-mature rapture of member (PROM) and antpartum hemorrhage (APH). This finding is inline elsewhere $[1,5,6,10$, $11]$.

The findings show that failed induction of labor is strongly associated with primipara mothers. This is consistent the study done in Jimma town [10], Hawassa town[11], Addis Ababa[12], Pakistan[14], Israel [27] and a systematic review done in USA [5]. Hence, preparation of the cervix before commencing induction in primipara women is recommended to improve success of induction with the current Federal Democratic Republic of Ethiopia-Ministry of Health (FDRE-MOH) guideline [28].

Failed induction is significantly associated with Bishop Score of 5 or less [AOR $=10.672(1.311-86.879)$, this is consistent the study done elsewhere $[10,13,14,17,18,27,29,30]$. It also supports the scientific findings of different literatures that the condition of the cervix at the start of induction is an important predictor, with the modified Bishop score being a widely used scoring system. Induction of labor results in high failure rate if the cervix is not ripe [29].

\section{Conclusion}

The magnitude of failure of labor induction was found $11.8 \%$ (95\% Cl: 8.7-15.3\%). Variables which increased the likelihood of failed induction were primi-parity, and unfavourable bishop score. Developing practice guidelines may help to prevent unwarranted case selection and help to reduce the current failure rates. The health care providers should assess and document the status of the cervix (using the Bishop score) to determine the probability of success and to select the appropriate method of induction. In addition, they need to consider induction of women with an unfavorable cervix is associated with high failure and a higher caesarean section.

\section{Limitations}

A research based on the secondary data suffers from incompleteness information. Details of socio demographic variables, such as educational level, and quality of obstetric services not addressed due to lack of documentation.

\section{Abbreviations}

AOR: Adjusted Odd Ratio; COR: Crude Odds Ratio; EDHS: Ethiopian Demographic and Health Survey; IOL: Induction of Labor; IUGR; Intrauterine Growth Restriction; NRFHRP: Non-Reassuring Fetal Heart Rate 
Pattern; PROM: Premature Rapture OF Membrane; NICU: Newborn Intensive Care Unit; SPSS: Statistical Package for Social Science; VIF: Variance inflation factor, WHO: World Health Organization.

\section{Declarations}

\section{Ethics approval and consent to participate}

This study protocol was approved by the School of Public Health, Aksum University, research ethics review committee. Communication with hospital administration made through formal letter obtained from the School of Public Health, Aksum University. The data was kept confidential.

\section{Consent for publication}

This manuscript does not contain any individual person's data so this section is not applicable.

\section{Availability of data and material}

All the required data are presented with in the manuscript.

\section{Competing interests}

The authors declare that they have no competing interests.

\section{Funding}

Nil.

\section{Authors' contributions}

All authors were equally contributed to this research. All authors read and approved the final manuscript.

\section{Acknowledgments}

The authors would like to acknowledge Axum St.Marry hospital for their permission to conduct this research. And also, we would like to acknowledge to data collector.

\section{References}

1. World Health Organization[WHO]. WHO recommendations for induction of labour: evidence base. 2011.

2. Vogel JP, Souza JP, Gülmezoglu AM. Patterns and outcomes of induction of labour in Africa and Asia: a secondary analysis of the WHO Global Survey on Maternal and Neonatal Health. PloS one. 2013;8(6):e65612. 
3. World Health Organization[WHO]. WHO recommendations: induction of labour at or beyond term: World Health Organization; 2018.

4. Grobman WA, Bailit J, Lai Y, Reddy UM, Wapner RJ, Varner MW, et al. Defining failed induction of labor. American journal of obstetrics and gynecology. 2018;218(1):122. e1-. e8.

5. Mozurkewich EL, Chilimigras JL, Berman DR, Perni UC, Romero VC, King VJ, et al. Methods of induction of labour: a systematic review. BMC pregnancy and childbirth. 2011;11(1):84.

6. Mozurkewich E, Chilimigras J, Koepke E, Keeton K, King V. Indications for induction of labour: a bestevidence review. BJOG: An International Journal of Obstetrics \& Gynaecology. 2009;116(5):626-36.

7. Hofmeyr GJ, Gulmezoglu AM, Alfirevic Z. Misoprostol for induction of labour: a systematic review. British journal of obstetrics and gynaecology. 1999;106(8):798-803. Epub 1999/08/24..

8. Caughey AB, Sundaram V, Kaimal AJ, Gienger A, Cheng YW, McDonald KM, et al. Systematic review: elective induction of labor versus expectant management of pregnancy. Annals of internal medicine. 2009;151(4):252-63.

9. Yeast JD, Jones A, Poskin M. Induction of labor and the relationship to cesarean delivery: a review of 7001 consecutive inductions. American journal of obstetrics and gynecology. 1999;180(3):628-33.

10. Girma W, Tseadu F, Wolde M. Outcome of Induction and Associated Factors among Term and PostTerm Mothers Managed at Jimma University Specialized Hospital: A Two Years' Retrospective Analysis. Ethiopian journal of health sciences. 2016;26(2):123-32.

11. Bekana Fekecha Hurissa, Mathewos Geta, and Tefera Belachew, Prevalence of Failed Induction of Labor and Associated Factors Among Women Delivered in Hawassa Public Health Facilities, Ethiopia, 2015. Journal of Women's Health Care, 2015. 4(5).

12. Bekana Fekecha Hurissa, Mathewos Geta, Tefera Belachew. Prevalence of Failed Induction of Labor and Associated Factors Among Women Delivered in Hawassa Public Health Facilities, Ethiopia, 2015. Journal of Women's Health Care. 2015;4(5).

13. Rouse DJ, Weiner SJ, Bloom SL, Varner MW, Spong CY, Ramin SM, et al. Failed labor induction: toward an objective diagnosis. Obstetrics and gynecology. 2011;117(2 0 1):267.

14. Khan NB, Ahmed I, Malik A, Sheikh L. Factors associated with failed induction of labour in a secondary care hospital. Journal of the Pakistan Medical Association: JPMA. 2012;62(1):6.

15. Park KH, Hong JS, Ko JK, Cho YK, Lee CM, Choi H, et al. Comparative study of induction of labor in nulliparous women with premature rupture of membranes at term compared to those with intact membranes: duration of labor and mode of delivery. Journal of Obstetrics and Gynaecology Research. 2006;32(5):482-8.

16. Banos N, Migliorelli F, Posadas E, Ferreri J, Palacio M. Definition of failed induction of labor and its predictive factors: two unsolved issues of an everyday clinical situation. Fetal diagnosis and therapy. 2015;38(3):161-9.

17. Gabbay-Benziv R, Hadar E, Ashwal E, Chen R, Wiznitzer A, Hiersch L. Induction of labor: does indication matter? Archives of gynecology and obstetrics. 2016;294(6):1195-201. 
18. Schoen C, Navathe R, editors. Failed induction of labor. Seminars in perinatology; 2015: Elsevier.

19. Montgomery KS. Apgar scores: examining the long-term significance. The Journal of perinatal education. 2000;9(3):5.

20. Banos N, Migliorelli F, Posadas E, Ferreri J, Palacio M. Definition of failed induction of labor and its predictive factors: two unsolved issues of an everyday clinical situation. Fetal diagnosis and therapy. 2015;38(3):161-9.

21. Rouse DJ, Owen J, Hauth JC. Criteria for failed labor induction: prospective evaluation of a standardized protocol. Obstetrics \& Gynecology. 2000;96(5):671-.

22. Edwards KI, Itzhak P. Estimated Date of Delivery (EDD). 2019.

23. Galal M, Symonds I, Murray H, Petraglia F, Smith R. Postterm pregnancy. Facts, views \& vision in ObGyn. 2012;4(3):175.

24. Giugliano E, Cagnazzo E, Milillo V, Moscarini M, Vesce F, Caserta D, et al. The risk factors for failure of labor induction: a cohort study. The Journal of Obstetrics and Gynecology of India. 2014;64(2):111-5.

25. Alaulikar VS, Arulkumaran S. Failed induction of labor: strategies to improve the success rates. Obstetrical \& Gynecological Survey. 2011;66(11):717-28.

26. Ekele BA, Oyetunji JA. Induction of labour at Usmanu Danfodiyo University Teaching Hospital, Sokoto. Tropical Journal of Obstetrics and Gynaecology. 2002;19(2):74-7.

27. Melamed N, Yariv O, Hiersch L, Wiznitzer, Arnon, Meizner I, Yogev Y. Labor induction with prostaglandin E2: characteristics of response and prediction of failure. The Journal of Maternal-Fetal \& Neonatal Medicine. 2013;26(2):132-6.

28. Federal Democratic Republic of Ethiopia Ministry of Health(FDRE-MoH). Managment Protocol on Selected Obstetrics Topics ,Addis Ababa,Ethiopia. 2010.

29. Berhan Y, Dwivedi A. Currently used oxytocin regimen outcome measures at term \& postterm. I: Outcome indicators in relation to parity \& indication for induction. Ethiopian medical journal. 2007;45(3):235-42.

30. Teixeira $\mathrm{C}$, Lunet $\mathrm{N}$, Rodrigues $\mathrm{T}$, Barros $\mathrm{H}$. The Bishop Score as a determinant of labour induction success: a systematic review and meta-analysis. Archives of gynecology and obstetrics. 2012;286(3):739-53.

\section{Figures}




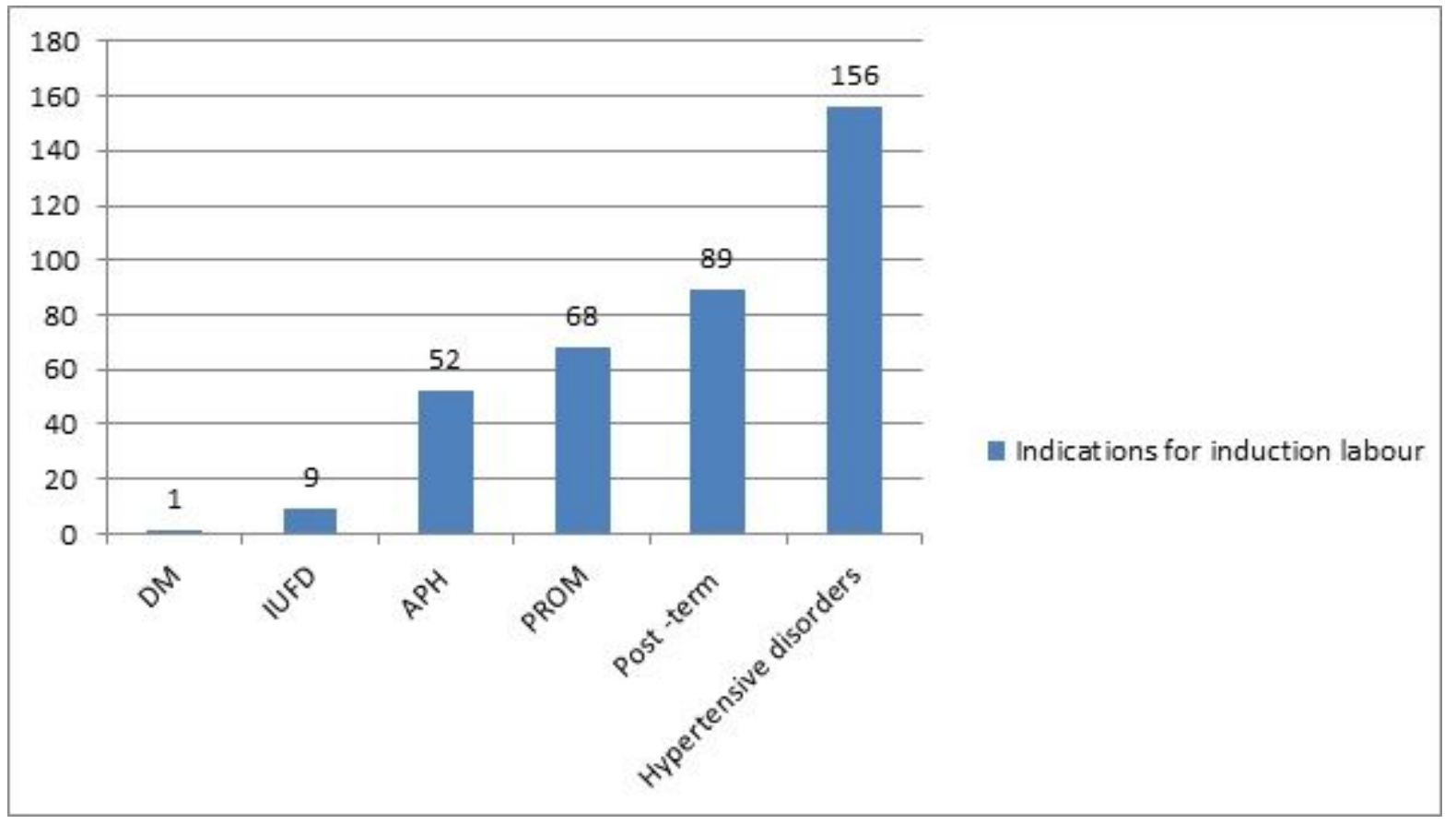

\section{Figure 1}

Indications for induction of labor, Tigray region, Ethiopia: a retrospective record review study from April 9, 2017- April 8, 2018.

\section{Supplementary Files}

This is a list of supplementary files associated with this preprint. Click to download.

- Questionnairefailureoflabourinduction.docx 